\title{
Atorvastatin Induced Erythema Multiforme
}

\author{
Gimenez- Garcia Rosa*, Gonzalez-Gonzalez Diego, Martinez-Martin Eva \\ Department of Dermatology, Hospital Rio Hortega, Valladolid, Spain
}

*Corresponding Author: Gimenez- Garcia Rosa, Department of Dermatology, Hospital Rio Hortega, Valladolid, Spain, E-mail: rosagim@hotmail.com

\begin{abstract}
Introduction: Atorvastatin is an inhibitor of hydroxymethylglutaryl-coenzyme A (HMG-CoA) reductase, used as a cholesterol-lowering medication and alleviate progression protected against high glucose-induced apoptosis in cardiomyocytes and alleviated experimental diabetic cardiomyopathy. Few cases of statins induced erythema multiforme have been described to date. We present a case of photoinduced erythema multiforme due to atorvastatin that, to our knowledge, has not been previously reported.
\end{abstract}

Case report: 49-year-old man with personal history of hyperlipidemia presented to us with a 3 months history of photoinduced lesions on the dorsum of his hands that he developed after starting treatment with atorvastatin.There was not mucous membrane involvement. He did not report herpes simplex infection.

Discusión: The most common triggers of erythema multiforme include drug intake, HSV infection, and exposures to the sun light giving rise to photosensitive erythema multiforme. Drug related erythema multiforme typically affect the oral mucose and may be associated with antibacterial (sulfonamides, penicilins, cephalosporins, quionolones), anticonvulsants (barbiturates, hydantoines) or analgesics. Photodistributed erythema multiforme also has been described after ingestions of drugs followed by sun exposure but few cases related with statins have been described thus far.

Conclusión: It is of importance to acknowledge the possible role of statins in a patient with erythema multiforme. Discontinuation of theses statins might result in a substantial improvement of lesions.

Keywords: Atorvastatin, Erythema multiforme, Cutaneous drug reaction

\section{INTRODUCTION}

Statins are the most prescribed medication internationally. Atorvastatin (ATOR) is an inhibitor of hydroxymethylglutaryl-coenzyme A (HMG-CoA) reductase and is used as a cholesterol-lowering medication. A recent study reported that ATOR alleviated progression protected against high glucose-induced apoptosis in cardiomyocytes and alleviated experimental diabetic cardiomyopathy $[1,2]$.

Cutaneous adverse effects induced by statins are uncommon [3]. Few cases of statins induced erythema multiforme have been described to date $[4,5]$. We present a case of EM due to atorvastatin that, to our knowledge, has not been previously reported.
A 49-year-old man with personal history of hyperlipidemia and hypothyroidism treated with levothyroxine presented to us with a 3 month history of photoinduced lesions on the dorsum of his hands that he developed after starting treatment with atorvastatin (Figure 1). There was not mucous membrane involvement. He did not report herpes simplex infection. The lesions improved after withdrawing the treatment and reappeared by reintroducing the statin in lower doses. Histopathologic examination of a skin biopsy demonstrated apoptotic keratinocytes in the epidermis basal, edema in the papillary dermis associate with interface dermatitis and perivascular lymphocytic infiltrate in the dermis (Figure 2).

\section{CASE Report}




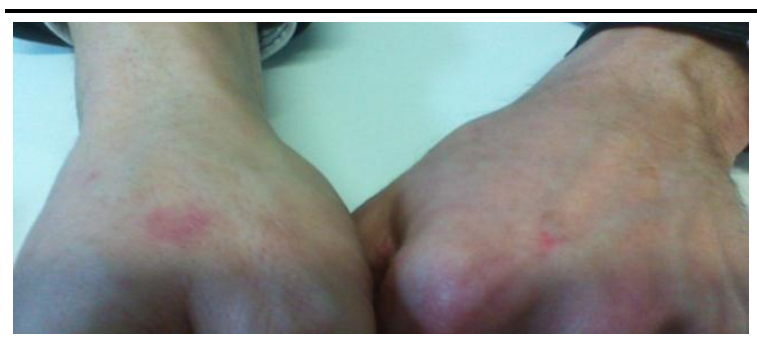

Figure1. Photo induced erithematous lesions on the dorsum of hands during the atorvastatin treatment.

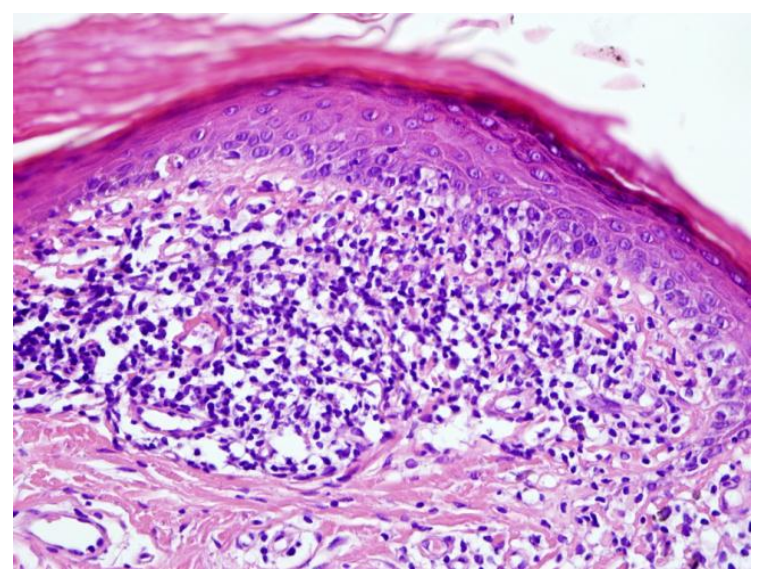

Figure2. Apoptotic keratinocytes in basal epidermis, edema in the papillary dermis with interface dermatitis and perivascular lymphocytic infiltrate in the dermis.

\section{DISCUSSION}

As the pharmacological base of cholesterol treatment, statins benefit has been reported in the primary and secondary prevention of cardiovascular disease. They reduce serum atherogenic lipoprotein concentrations by blocking hepatic cholesterol synthesis and increasing the availability of low density LDL receptors in hepatocytes. The most commonly reported side effects include hepatotoxicity, abdominal discomfort, headache, myalgias and myositis [6,7].

Statin-associated side effects include myopathy, diabetes mellitus, hepatopathy, auntoinmune reactions and dermatological lesions such as uricaria, eczema, dermatitis, porfiria cutanea tarda, phototoxicity, liquenoid eruptions, interstitial granulomatous dermatitis, lupus erythematosus, dermatomyositis. Few cases of erythema multiforme related with statins have been described thus far [3-9].

Erythema multiforme (EM) is an acute, selflimiting disease of the skin and mucocutaneos membranes characterized by symmetrically distributed eritematous macule-papules. Most often located on acral regions, EM has a tendency for recurrences. Histopathological examination shows perivascular mononuclear cells infiltrate and edema in the papillary dermis, associated with interface dermatitis, vacuolar damage and apoptosis of basal keratinocytes, resulting in areas of epidermal necrosis $[8,9]$.

The most common triggers of erythema multiforme include drug intake, HSV infection, and exposures to the sun light giving rise to photosensitive erythema multiforme. Drug related erythema multiforme typically affect the oral mucose and may be associated with antibacterials (sulfonamides, penicilins, cephalosporins, quionolones), anticonvulsants (barbiturates, hydantoines) or analgesics. Photodistributed erythema multiforme also has been described after ingestions of other drugs like ofloxacin and tocilizumab [12-14]. Erythema multiforme induced by simvastatin, pravastatin and rosuvastatin has been previously described $[4,5,13]$. Nonetheless, this is the first case of erythema multiforme induced by atorvastatin.

\section{REFERENCES}

[1] Miller PE, Martin SS. Approach to statin use in 2016: an Update. Curr Atheroscler Rep 2016; 18:20.

[2] Ren XM Zuo GF, Wu W, Luo J, Ye P, Chen $\mathrm{SL}, \mathrm{Hu} \mathrm{ZY}$. Atorvastatin Alleviates Experimental Diabetic Cardiomyopathy by Regulating the GSK-3 $\beta-P P 2 A c-N F-\kappa B$ Signaling Axis. PLoS One. 2016; 16; 11: e0166740.

[3] Jowkar F, Namazi MR. Statins in dermatology. Int J Dermatol. 2010;49:1235-1243

[4] Rivera R, Nicolau J, Terrasa F, Masmiquel L. Rosuvastatine induced erythema multiforme. 2013. MedClin (Barc). 2013;140 :523-525.

[5] Rodriguez-Pazos L, Sanchez-Aguilar D, Rodrıguez-Granados MT, Pereiro-Ferreiros MM, Toribio J. Erythema multiforme photo induced by statins. Photodermatol Photo immunol Photomed. 2010; 26:216-8.

[6] Thai SA, Reeve E, Hilmer SN, Qi K, Pearson SA, Gnjidic D. Prevalence of statin-drug interactions in older people. Eur J Pharmacol 2016; 72:513-21

[7] Beatrice A. Golomb, M.D., Ph.D and Marcella A. Evans, B.S..Statin Adverse Effects: A Review of the Literature and Evidence for a Mitochondrial Mechanism. Cardiovasc Drugs. 2008; 8: 373-418.

[8] L. Rodríguez-Pazos, S. Gómez-Bernal, M.T. Rodríguez-Granados, J. Toribio. Eritema multiforme fotodistribuido. Acta sermo sifiliogr. 2013; 104(8): 645-653.

[9] Farthing P, Bagan JV, Scully C. Mucosal disease series. Number IV. Erythema multiforme. Oral Dis. 2005; 11:261-7. 
[10] Shreyas N Shah, Girish R Chauhan, B.S Manjunatha, Kapil Dagrus Drug Induced Erythema Multiforme: Two Case Series with Review of Literature. J Clin Diagn Res. 2014; 8: ZH01-ZH04.

[11] Nettis E, Giordano D, Pierluigi T, Ferrannini A, Tursi A. Erythema multiforme-like rash in a patient sensitive to ofloxacin. Acta Derm Venereol. 2002;82:395-6.

[12] Hamada K, Sawada Y, Yamaguchi T, Ohmori S, Omoto D, Haruyama S, Yoshioka M, Nishio D, Nakamura M. Photosensitivity due to cilizumab presenting with erythema multiforme-like lesions. Eur J Dermatol. 2016; 26:503-504.

[13] Rodríguez-Pazos L, Gómez-Bernal S, Rodríguez-Granados M.T, Toribio J. Eritema multiforme foto distribuido. Actas Dermosifiliogr. 2013; 104: 645-653

[14] Calzavara Pinton PG, Venturini M, Capezzera $\mathrm{R}$, Zane C, FacchettiF. Photosensitive erythema multiforme and erythema multiforme-like polymorphous light eruption. Photodermatol Photoimmunol Photomed. 2003; 19:157-159.

Citation: Gimenez- Garcia Rosa, Gonzalez-Gonzalez Diego, Martinez-Martin Eva. Atorvastatin Induced Erythema Multiforme. 2017;2(1):19-21. doi: dx.doi.org/10.20431/2456-0022.0201004.

Copyright: () 2017 Authors. This is an open-access article distributed under the terms of the Creative Commons Attribution License, which permits unrestricted use, distribution, and reproduction in any medium, provided the original author and source are credited. 